\title{
POETRY
}

\section{For a classmate}

The last time that I saw you, you were stoned, Pleasantly so, leaning against the bar Of the Red Dragon and drinking on the tab Of the third year class with the rest of us.

You were a connoisseur of chemicals, It's fair to say - everyone knew as much But no one seemed to know how you acquired A tank of nitrous oxide, let alone How you ever got it to your bedroom Where your mother found you in the morning. The coroner pronounced it accidental, But you had just spent three years studying The very physiology you altered With such persistence and apparent grace I was not the only one with doubts. The last thing I remember that you said Was how you planned to match in Anesthesia, An irony that deepened all too soon. Now every time I dial up the blue knob And watch the bobbin slowly rise and turn, Your face floats through my mind like a ghost, Clear and colourless, ethereal.

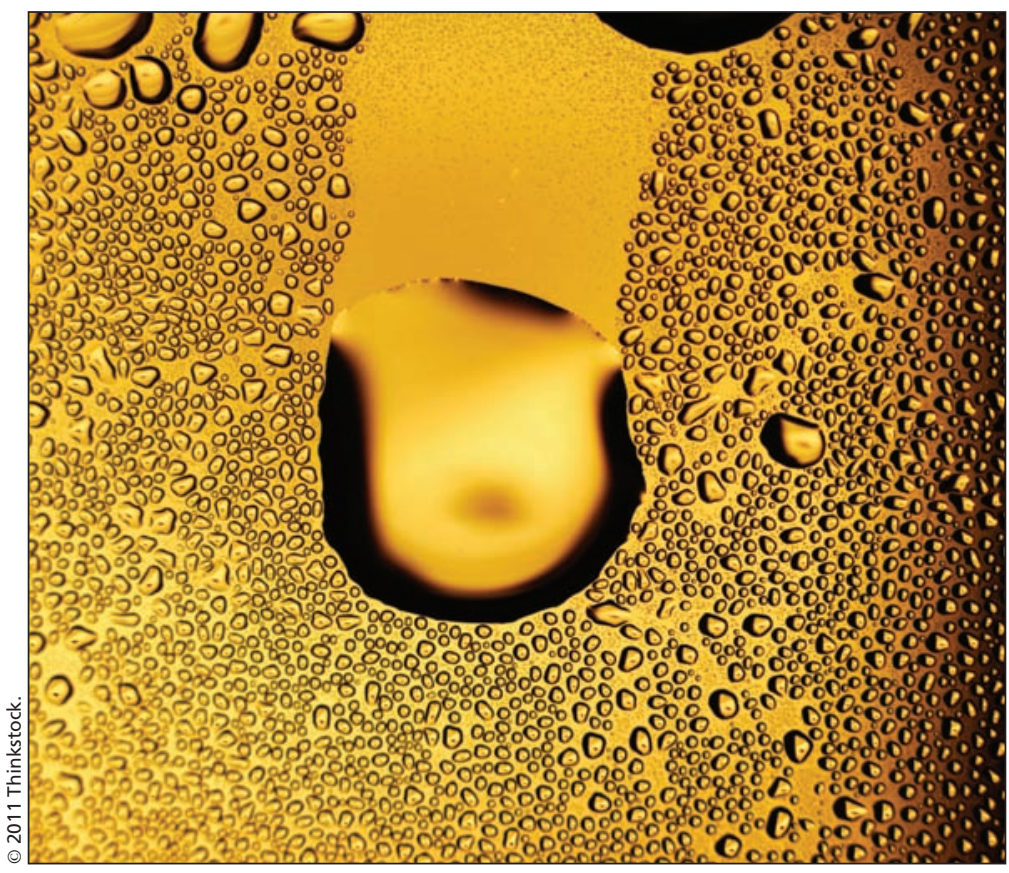

\section{Stephen Harvey MD}

Assistant professor of anesthesiology

Vanderbilt University

Nashville, Tenn.

Dr. Harvey's poetry has appeared in JAMA, Anesthesiology, 14 by 14, and The Road Not Taken.

CMAJ 2011. DOI:10.1503/cmaj.110063 